\title{
Mental and Reproductive Health Correlates of Academic Performance among Debre Berhan University Female Students, Ethiopia: The Case of Premenstrual Dysphoric Disorder
}

\author{
Sisay Mulugeta Alemu, ${ }^{1}$ Tesfa Dejenie Habtewold, ${ }^{2}$ and Yohannes Gebreegziabhere Haile ${ }^{3}$ \\ ${ }^{1}$ Mental Health and Psychosocial Support Program, International Medical Corps, Dolo Ado, Ethiopia \\ ${ }^{2}$ Department of Epidemiology and Rob Giel Research Center, University of Groningen, Groningen, Netherlands \\ ${ }^{3}$ Department of Nursing, Debre Berhan University, Debre Berhan, Ethiopia \\ Correspondence should be addressed to Tesfa Dejenie Habtewold; tesfadej2003@gmail.com
}

Received 22 December 2016; Accepted 24 April 2017; Published 29 May 2017

Academic Editor: Alberto Raggi

Copyright ( 2017 Sisay Mulugeta Alemu et al. This is an open access article distributed under the Creative Commons Attribution License, which permits unrestricted use, distribution, and reproduction in any medium, provided the original work is properly cited.

\begin{abstract}
Background. Globally 3 to $8 \%$ of reproductive age women are suffering from premenstrual dysphoric disorder (PMDD). Several mental and reproductive health-related factors cause low academic achievement during university education. However, limited data exist in Ethiopia. The aim of the study was to investigate mental and reproductive health correlates of academic performance. Methods. Institution based cross-sectional study was conducted with 667 Debre Berhan University female students from April to June 2015. Academic performance was the outcome variable. Mental and reproductive health characteristics were explanatory variables. Two-way analysis of variance (ANOVA) test of association was applied to examine group difference in academic performance. Result. Among 529 students who participated, 49.3\% reported mild premenstrual syndrome (PMS), 36.9\% reported moderate/severe PMS, and 13.8\% fulfilled PMDD diagnostic criteria. The ANOVA test of association revealed that there was no significant difference in academic performance between students with different level of PMS experience $(F$-statistic $=0.08, p$ value $=0.93)$. Nevertheless, there was a significant difference in academic performance between students with different length of menses $(F$-statistic $=5.15, p$ value $=0.006)$. Conclusion. There was no significant association between PMS experience and academic performance, but on the other hand, the length of menses significantly associated with academic performance.
\end{abstract}

\section{Introduction}

Menstrual cycle is the orderly cyclic hormone production and parallel proliferation of the uterine lining to prepare for implantation of the embryo [1]. Most women report mood symptoms, behavioral changes, and physical symptoms during the menstrual cycle; however, these symptoms resolve for the rest of time between menstrual cycles. This group of symptoms are first named as premenstrual tension by Frank and later renamed to premenstrual syndrome by Greene and Dalton in 1953 [2].

There are more than 150 premenstrual symptoms registered in 10th revision of the International Statistical Classification of Diseases and Related Health Problems (ICD-10) [3]. Premenstrual syndrome (PMS) is the presence of at least one out of fourteen symptoms registered in the fifth text edition of Diagnostic and Statistical Manual of Mental Disorders (DSM-5) [4]. Premenstrual dysphoric disorder (PMDD), a severe form of PMS, is defined as the presence of at least five out of eleven DSM-5 mood or behavioral or physical symptoms with the substantial interference of daily activities [4].

Even though up to $80 \%$ of women experience mild to severe premenstrual symptoms [5-9], they consider these symptoms as a natural event [6] and do not seek medical advice [10]. According to the DSM-5 criteria, the prevalence of PMDD was 3 to $8 \%$ [11]. In addition, $18 \%$ of reproductive age women suffered from moderate to severe premenstrual symptoms [12].

Previous studies showed that biological, psychological, and social-cultural factors cause PMDD [13]. These factors 
include educational and marital status, genetic predisposition, age, pain during menses, amount of menstrual bleeding, history of physical and psychiatric illness, treatment seeking behavior, history of traumatic event, sleeping hour, physical exercise, and maternal history of PMS [14-26]. Women become symptomatic when the social and psychological stressors induce biochemical (hormone and neurotransmitter) changes [2].

Among others, school absenteeism and poor academic performance were the deleterious effects of PMDD [27]. Moreover, PMDD has been associated with suicide and accident rate, major depressive disorder, high job absenteeism, poor quality of life, and poor family and coworkers relationship $[28,29]$.

Despite a considerable effect on women daily functioning, the association between PMS experience and academic performance has given little attention [11]. Thus, the aim of this study was to investigate mental and reproductive health correlates of academic performance among female students.

\section{Methods and Materials}

2.1. Population and Procedure. Institution based cross-sectional study was conducted at Debre Berhan University from April to June 2015. Undergraduate students who enrolled in 2014/2015 full-time study, who were capable of independent communication, and who provided informed written consent were included. All students were selected by multistage cluster sampling technique (design effect $=2$ ). First, 5 out of 8 colleges were selected by simple random sampling technique. Second, 14 departments representing $40 \%$ of departments at Debre Berhan University were selected using simple random sampling technique. Finally, student batches (1st, 2nd, and 3rd year) were selected randomly and data was collected from the entire students. The data was collected after the class.

2.2. Sample Size Determination. The sample size was determined by single population proportion formula considering the following assumptions: $27 \%$ prevalence of PMDD in Ethiopian university students [19] and 95\% confidence level. After adjustment for the design effect of 2 and $10 \%$ nonresponse rate, the final sample size was 667.

2.3. Instrument. Data was collected from 14 departments using pretested self-administered questionnaire. The questionnaire has four parts: part 1, sociodemographic characteristics; part 2, menstrual cycle characteristics; part 3, treatment seeking behavior and general health status; part 4, premenstrual symptoms and functionality. Premenstrual symptoms screening tool (PSST) was used to assess PMDD. The PSST includes a list of premenstrual psychiatric and physical symptoms, and a measure of functional impairment in accordance with DSM-5 criteria. PSST for adolescents aged $\geq 18$ years has excellent internal consistency, Cronbach's alpha of 0.91 , and content validity of 0.91 [30].

2.4. Variables. Academic performance was the primary outcome variable. Self-reported cumulative grade point average (CGPA) was used as a proxy measure of academic performance. Premenstrual symptoms experience, history of depression, history of traumatic events, sleeping hour, pain during menses, length of menses, amount of menstrual bleeding, and duration of menses were the explanatory variables. Premenstrual symptoms experience rated as no/mild PMS, moderate/severe PMS, and severe PMS or PMDD. PMDD was diagnosed if at least one out of four "core PMS" symptoms rated as "severe," at least four additional PMS symptoms rated either "moderate" or "severe," and at least one out of five "area of functioning" items rated "severe." PMDD was the secondary outcome variable. Moderate/severe PMS was diagnosed if at least one out of four "core PMS" symptoms rated either "moderate" or "severe," at least four additional PMS symptoms rated either "moderate" or "severe," and at least one out of five "area of functioning" items rated "moderate" or "severe" [31]. If the students did not fulfill the above classifications, they were diagnosed as "no/mild PMS." Level of pain and amount of bleeding during menses were measured and rated based on the subjective experience of students.

\section{Data Processing and Analysis}

Data was coded, entered, and cleaned using EPI Info version 3.5.1. Before analysis, continuous variables were grouped based on previous research and internationally recommended cut-off value [1]. To examine the risk factors of PMDD, first, all variables were fitted to the bivariate logistic regression model. Then, variables were included in the final multiple logistic regression model if $p$ value reached 0.05 . Finally, independently associated risk factors were identified based on 0.05 significance level. The strength of association was determined using odds ratios with $95 \%$ confidence interval. Two-way ANOVA test of association was applied to investigate the association between academic performance and mental and reproductive health-related factors. In addition, Bonferroni post hoc test was done for multiple comparisons of groups difference in academic performance. Statistical Package for Social Science (SPSS) version 20.0 (IBM SPSS Corp.) was used for data analysis. The study was adherent to the strengthening of the reporting of observational studies in epidemiology (STROBE) statement (see Supplementary File 1: STROBE statement in the Supplementary material available online at https://doi.org/10.1155/2017/9348159).

\section{Ethics Approval and Consent to Participate}

Debre Berhan University, Institute of Health Science and Medicine Ethical Review Board, approved the study protocol. Participation was voluntary and data was collected anonymously after obtaining written consent from each student.

\section{Results}

5.1. Biopsychosocial Characteristics. In total, 529 students completed the self-administered questionnaire with the response rate of $80 \%$. The main reasons for nonresponse were a lack of interest and shortage of time. The mean age of students was 20.5 years $(\mathrm{SD} \pm 1.54)$. More than two-thirds 
TABLE 1: Premenstrual symptoms and functional interference, June 2015.

\begin{tabular}{|c|c|c|c|c|c|c|c|c|}
\hline & \multicolumn{2}{|c|}{ Not at all } & \multicolumn{2}{|c|}{ Mild } & \multicolumn{2}{|c|}{ Moderate } & \multicolumn{2}{|c|}{ Severe } \\
\hline & No & $\%$ & No & $\%$ & No & $\%$ & No & $\%$ \\
\hline \multicolumn{9}{|l|}{ List of symptoms } \\
\hline Anger/irritability & 180 & $34.0 \%$ & 160 & $30.2 \%$ & 139 & $26.3 \%$ & 50 & $9.5 \%$ \\
\hline Anxiety/tension & 153 & $28.9 \%$ & 162 & $30.6 \%$ & 156 & $29.5 \%$ & 58 & $11.0 \%$ \\
\hline Tearfulness/increased sensitivity to rejection & 239 & $45.2 \%$ & 159 & $30.1 \%$ & 102 & $19.3 \%$ & 29 & $5.5 \%$ \\
\hline Depressed mood/hopelessness & 184 & $34.8 \%$ & 140 & $26.5 \%$ & 148 & $28.0 \%$ & 57 & $10.8 \%$ \\
\hline Decreased interest in work activity & 137 & $25.9 \%$ & 138 & $26.1 \%$ & 174 & $32.9 \%$ & 80 & $15.1 \%$ \\
\hline Decreased interest in home activity & 126 & $23.9 \%$ & 167 & $31.6 \%$ & 163 & $30.9 \%$ & 72 & $13.6 \%$ \\
\hline Decreased interest in social activity & 158 & $29.9 \%$ & 155 & $29.4 \%$ & 148 & $28.0 \%$ & 67 & $12.7 \%$ \\
\hline Difficulty concentrating & 206 & $38.9 \%$ & 150 & $28.4 \%$ & 119 & $22.5 \%$ & 54 & $10.2 \%$ \\
\hline Fatigue/lack of energy & 110 & $20.8 \%$ & 143 & $27.0 \%$ & 165 & $31.2 \%$ & 111 & $21.0 \%$ \\
\hline Overeating/food craving & 282 & $53.3 \%$ & 158 & $29.9 \%$ & 65 & $12.3 \%$ & 24 & $4.5 \%$ \\
\hline Insomnia/difficulty of sleeping & 264 & $49.9 \%$ & 119 & $22.5 \%$ & 101 & $19.1 \%$ & 45 & $8.5 \%$ \\
\hline Hypersomnia (need more sleep) & 150 & $28.4 \%$ & 139 & $26.3 \%$ & 143 & $27.0 \%$ & 97 & $18.3 \%$ \\
\hline Feeling overwhelmed or out of control & 228 & $43.1 \%$ & 144 & $27.2 \%$ & 105 & $19.8 \%$ & 52 & $9.8 \%$ \\
\hline Physical symptoms (e.g., muscle pain, bloating) & 130 & $24.6 \%$ & 105 & $19.8 \%$ & 146 & $27.6 \%$ & 148 & $28.0 \%$ \\
\hline \multicolumn{9}{|l|}{ Area of functioning } \\
\hline Symptoms interfered work efficiency or productivity & 163 & $30.8 \%$ & 153 & $28.9 \%$ & 162 & $30.6 \%$ & 51 & $9.6 \%$ \\
\hline Symptoms interfered relationship with coworkers & 178 & $33.6 \%$ & 148 & $28.0 \%$ & 144 & $27.2 \%$ & 59 & $11.2 \%$ \\
\hline Symptoms interfered relationship with family & 180 & $34.0 \%$ & 144 & $27.2 \%$ & 115 & $21.7 \%$ & 90 & $17.0 \%$ \\
\hline Symptoms interfered social life activity & 171 & $32.3 \%$ & 150 & $28.4 \%$ & 150 & $28.4 \%$ & 58 & $11.0 \%$ \\
\hline Symptoms interfered home responsibility & 174 & $32.9 \%$ & 164 & $31.0 \%$ & 127 & $24.0 \%$ & 64 & $12.1 \%$ \\
\hline
\end{tabular}

(70.1\%) of students were single, $50.3 \%$ were first year, and $72.4 \%$ were from Amhara ethnic group. On average students slept 8 (SD \pm 2.22 ) hours per day. The average menstrual cycle was 29.1 days $(S D \pm 9.5)$. More than half $(54.3 \%)$ of students suffered from moderate pain during menses. The mean duration of menses was 4.31 days (SD \pm 1.45 ). Furthermore, $13.2 \%$ of students reported heavy menstrual bleeding.

5.2. Premenstrual Symptoms Experience. Almost all students (95.5\%) had at least one mild premenstrual symptom, and $85.8 \%$ had moderate or severe symptoms. Fatigue or lack of energy $(89.2 \%)$ was the most prevalent symptom followed by decreased interest in home activity (76.1\%). Insomnia (50.1\%) and overeating $(46.7 \%)$ were the least prevalent symptoms (Table 1) Based on the DSM-5 criteria, $49.3 \%$ students were diagnosed with no/mild PMS, 36.9\% moderate/severe PMS, and $13.8 \%$ severe PMS or PMDD (Figure 1).

\section{Academic Performance}

The mean cumulative grade point average (CGPA) was 2.66 $(\mathrm{SD} \pm 0.51)$. Furthermore, $97.4 \%$ of students had the CGPA of $\geq 2.0$ and $46.5 \%$ of students had above the mean CGPA. The ANOVA test of association revealed that the mean CGPA of students who fulfilled PMDD criteria was not significantly different from students without PMDD $(F$-statistic $=0.08, p$ value $=0.93)$. On the other hand, the mean CGPA of students with $<21$ days, $21-35$ days, and $>35$ days of length of menses was significantly different. Multiple comparisons following

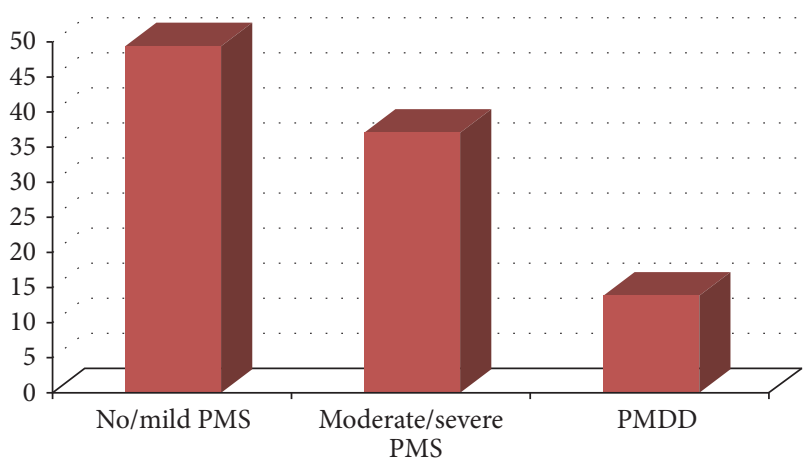

FIGURE 1: Frequency distribution of premenstrual symptoms experience, June 2015 .

Bonferroni post hoc test showed that the mean CGPA of students with $<21$ days of length of menses was significantly low compared to students with $21-35$ days ( $p$ value $=0.023$ ) and $>35$ days $(p$ value $=0.006)$ of length of menses $($ Table 2$)$.

\section{Associated Factors of PMDD}

The bivariate statistical modeling showed that pain during menses, amount of menstrual bleeding, maternal history of PMS, history of depression, psychiatric morbidity other than depression, and history of traumatic event were the significant risk factors of PMDD. Following multivariate modeling only pain during menses, amount of menstrual bleeding, 
TABLE 2: Mental and reproductive health-related correlates of academic performance, June 2015.

\begin{tabular}{|c|c|c|c|c|c|}
\hline Variables & $N=529$ & Mean CGPA & 95\% CI of mean CGPA & $F$-statistic & $p$ value \\
\hline \multicolumn{6}{|l|}{ Premenstrual symptoms } \\
\hline No/mild PMS & 261 & 2.67 & $2.61-2.73$ & \multirow{3}{*}{0.08} & \multirow{3}{*}{0.93} \\
\hline Moderate/severe PMS & 195 & 2.66 & $2.58-2.73$ & & \\
\hline PMDD & 73 & 2.64 & $2.53-2.76$ & & \\
\hline \multicolumn{6}{|l|}{ History of depression } \\
\hline Yes & 48 & 2.69 & $2.54-2.85$ & \multirow{2}{*}{0.19} & \multirow{2}{*}{0.66} \\
\hline No & 481 & 2.65 & $2.61-2.70$ & & \\
\hline \multicolumn{6}{|c|}{ History of any psychiatric morbidity other than depression } \\
\hline Yes & 57 & 2.60 & $2.48-2.72$ & \multirow{2}{*}{0.84} & \multirow{2}{*}{0.36} \\
\hline No & 472 & 2.66 & $2.62-2.71$ & & \\
\hline \multicolumn{6}{|l|}{ History of traumatic event } \\
\hline Yes & 96 & 2.65 & $2.55-2.76$ & \multirow{2}{*}{0.03} & \multirow{2}{*}{0.86} \\
\hline No & 433 & 2.66 & $2.61-2.71$ & & \\
\hline \multicolumn{6}{|l|}{ Sleeping status } \\
\hline$\leq 5.9$ hours/day & 44 & 2.65 & $2.48-2.82$ & \multirow{3}{*}{0.22} & \multirow{3}{*}{0.80} \\
\hline 6.0-7.9 hours/day & 104 & 2.63 & $2.54-2.73$ & & \\
\hline$\geq 8.0$ hours/day & 380 & 2.67 & $2.62-2.72$ & & \\
\hline \multicolumn{6}{|l|}{ Pain during menses } \\
\hline No & 56 & 2.67 & $2.53-2.82$ & \multirow{4}{*}{0.61} & \multirow{4}{*}{0.60} \\
\hline Minimal & 118 & 2.71 & $2.61-2.80$ & & \\
\hline Moderate & 257 & 2.65 & $2.58-2.71$ & & \\
\hline Severe & 98 & 2.62 & $2.52-2.71$ & & \\
\hline \multicolumn{6}{|l|}{ Length of menses } \\
\hline$<21$ days & 21 & 2.36 & $2.18-2.54$ & \multirow{3}{*}{5.15} & \multirow{3}{*}{0.006} \\
\hline 21-35 days & 487 & 2.66 & $2.62-2.71$ & & \\
\hline$>35$ days & 21 & 2.85 & $2.61-3.09$ & & \\
\hline \multicolumn{6}{|c|}{ Amount of menstrual bleeding } \\
\hline Minimal & 103 & 2.61 & $2.51-2.71$ & \multirow{3}{*}{1.06} & \multirow{3}{*}{0.35} \\
\hline Moderate & 356 & 2.68 & $2.63-2.73$ & & \\
\hline Heavy & 70 & 2.62 & $2.49-2.75$ & & \\
\hline \multicolumn{6}{|l|}{ Duration of menses } \\
\hline$\leq 3$ days & 166 & 2.64 & $2.56-2.71$ & \multirow{2}{*}{0.39} & \multirow{2}{*}{0.53} \\
\hline$\geq 4$ days & 363 & 2.67 & $2.61-2.72$ & & \\
\hline
\end{tabular}

and treatment seeking behavior persisted as a significant associated risk factor of PMDD.

Students who had severe pain during menses were 6.5 times more likely to develop PMDD compared to those who had no pain $(\mathrm{AOR}=6.5 ; 95 \% \mathrm{CI}=1.6-43.7)$. Students who had heavy menstrual bleeding were 2.8 times more likely to develop PMDD compared to those who had minimal bleeding $(\mathrm{AOR}=2.8 ; 95 \% \mathrm{CI}=1.2-7.1)$. Moreover, students who took the nonprescribed drug particularly pain-killers during menses were 8.5 times more likely to develop PMDD as compared to students who have used other options to manage symptoms $(\mathrm{AOR}=8.5 ; 95 \% \mathrm{CI}=1.5-46.6)$ (Table 3$)$.

\section{Discussion}

There was no significant association between premenstrual symptoms (PMS) experience and academic performance, but on the other hand, the length of menses significantly associated with academic performance. Based on the DSM5 criteria, $49.3 \%$ of students were diagnosed with no/mild PMS, 36.9\% moderate/severe PMS, and 13.8\% severe PMS or PMDD. Pain during menses, amount of menstrual bleeding, and treatment seeking behavior were risk factors of premenstrual dysphoric disorder (PMDD).

The first objective of this study was to assess the association between academic performance and mental and reproductive health-related factors. In contrary to another study in Ethiopia [27], the current study showed that there was no significant difference in academic performance between students who fulfilled PMDD criteria and without PMDD. This does not imply that PMDD had no relevant effect on student academic performance. Therefore, this nonsignificant result might be due to two reasons. Primarily, this study had used cumulative grade point average (CGPA), which might be affected by previous semester or year grade. This justification was supported by the finding that half of the students were 
TABLE 3: Bivariate and multiple logistic regression model of biopsychosocial risk factors and PMDD, June 2015.

\begin{tabular}{|c|c|c|c|c|}
\hline \multirow{2}{*}{ Variables (reference category) } & \multicolumn{2}{|c|}{ PMDD status } & \multirow{2}{*}{ Crude OR $(95 \%$ CI $)$} & \multirow{2}{*}{ Adjusted OR (95\% CI) } \\
\hline & $n / \%($ no) & $n / \%$ (yes) & & \\
\hline Current age, $\geq 20(\leq 19)$ & $356 / 67.3$ & $58 / 10.9$ & $1.1(0.6-2.1)$ & \\
\hline \multicolumn{5}{|l|}{ Marital status (single) } \\
\hline Engaged & $109 / 20.6$ & $19 / 3.6$ & $1.2(0.6-2.1)$ & \\
\hline Married & $24 / 4.5$ & $6 / 1.1$ & $2.0(0.6-4.1)$ & \\
\hline \multicolumn{5}{|l|}{ Ethnicity (Amhara) } \\
\hline Oromo & $67 / 12.7$ & $12 / 2.2$ & $1.1(0.5-2.1)$ & \\
\hline Tigre & $20 / 3.8$ & $2 / 0.4$ & $0.6(0.1-2.2)$ & \\
\hline Others & $40 / 7.6$ & $5 / 1.0$ & $0.8(0.3-1.8)$ & \\
\hline \multicolumn{5}{|l|}{ Religion (orthodox) } \\
\hline Muslim & $22 / 4.2$ & $2 / 0.4$ & $0.5(0.1-1.8)$ & \\
\hline Protestant & $51 / 9.6$ & $5 / 1.0$ & $0.6(0.2-1.4)$ & \\
\hline \multicolumn{5}{|l|}{ Field of study (natural and computational science) } \\
\hline Agriculture science & $55 / 10.3$ & $9 / 1.7$ & $1.2(0.5-2.6)$ & \\
\hline Social science & $102 / 19.3$ & $15 / 2.8$ & $1.1(0.5-2.1)$ & \\
\hline Business and economics & $75 / 14.2$ & $21 / 4.0$ & $2.0(1.1-3.8)$ & \\
\hline Health science & $34 / 6.4$ & $2 / 0.4$ & $0.4(0.1-1.5)$ & \\
\hline \multicolumn{5}{|l|}{ Bach (first year) } \\
\hline Second year & $134 / 25.3$ & $24 / 4.5$ & $1.2(0.7-2.1)$ & \\
\hline Third year & $90 / 17.0$ & $15 / 2.8$ & $1.1(0.6-2.2)$ & \\
\hline \multicolumn{5}{|l|}{ Daily sleeping hour ( $<5.9 \mathrm{hrs})$} \\
\hline $6.0-7.9 \mathrm{hrs}$ & $90 / 17.0$ & $14 / 2.6$ & $0.7(0.3-1.9)$ & \\
\hline$\geq 8 \mathrm{hrs}$ & $329 / 62.2$ & $51 / 9.6$ & $0.7(0.3-1.7)$ & \\
\hline Age at first menses $\geq 15$ years ( $\leq 14$ years) & $296 / 56.1$ & $50 / 9.4$ & $1.2(0.7-2.0)$ & \\
\hline \multicolumn{5}{|l|}{ Pain during menses (no pain) } \\
\hline Minimal & $108 / 20.4$ & $10 / 1.9$ & $2.5(0.6-16.6)$ & $2.2(0.5-15.5)$ \\
\hline Moderate & $228 / 43.1$ & $29 / 5.5$ & $3.4(1.0-21.6)$ & $2.8(0.7-18.6)$ \\
\hline Severe & $66 / 12.5$ & $32 / 6.0$ & $13.1(3.7-83.1)^{*}$ & $6.5(1.6-43.7)^{*}$ \\
\hline \multicolumn{5}{|l|}{ Amount of menses (minimal) } \\
\hline Moderate & $318 / 6.1$ & $38 / 7.2$ & $1.0(0.5-1.9)$ & $1.1(0.5-2.5)$ \\
\hline Heavy/severe & $47 / 8.9$ & $23 / 4.3$ & $3.7(1.7-8.3)^{*}$ & $2.8(1.2-7.1)^{*}$ \\
\hline Contraceptive use (nonuse) & $23 / 4.3$ & $3 / 0.6$ & $0.8(0.2-2.4)$ & \\
\hline \multicolumn{5}{|l|}{ Length of menses ( $\leq 21$ days) } \\
\hline 21-35 days & $417 / 78.8$ & $70 / 13.2$ & $1.6(0.5-10.1)$ & \\
\hline$\geq 35$ days & $20 / 3.8$ & $1 / 0.2$ & $0.5(0.02-5.4)$ & \\
\hline Menses for $\geq 4$ days ( $\leq 3$ days) & $311 / 58.8$ & $52 / 9.8$ & $1.2(0.7-2.0)$ & \\
\hline \multicolumn{5}{|l|}{ Treatment seeking behavior (other) } \\
\hline Nonprescribed drug & $8 / 1.6$ & $8 / 1.6$ & $14.0(3.0-64.5)^{*}$ & $8.5(1.5-46.6)^{*}$ \\
\hline Prescribed drug & $50 / 9.4$ & $12 / 2.2$ & $3.4(0.9-12.7)$ & $2.6(0.6-10.8)$ \\
\hline Sleep & $252 / 47.6$ & $35 / 6.6$ & $2.0(0.6-6.6)$ & $1.7(0.5-6.7)$ \\
\hline Exercise & $54 / 10.2$ & $6 / 1.1$ & $1.6(0.4-6.6)$ & $1.4(0.3-6.8)$ \\
\hline Diet change & $50 / 9.4$ & $9 / 1.7$ & $2.5(0.6-9.9)$ & $2.0(0.5-9.0)$ \\
\hline History of depression (no) & $36 / 6.8$ & $12 / 2.2$ & $2.3(1.1-4.5)^{*}$ & $1.5(0.6-3.2)$ \\
\hline History of psychiatric morbidity other than depression (no) & $44 / 8.3$ & $13 / 2.4$ & $2.0(1.1-3.9)^{*}$ & $1.3(0.6-2.8)$ \\
\hline History of physical morbidity (no) & $157 / 29.7$ & $28 / 5.3$ & $1.2(0.7-1.9)$ & \\
\hline Parental history of depression (no) & $31 / 5.9$ & $5 / 0.9$ & $1.0(0.3-2.5)$ & \\
\hline History of traumatic event (no) & $76 / 14.4$ & $20 / 3.8$ & $1.9(1.1-3.3)^{*}$ & $1.5(0.8-2.8)$ \\
\hline Mothers history of PMS & $51 / 9.6$ & $17 / 3.2$ & $2.4(1.3-4.4)^{*}$ & $1.8(0.8-3.5)$ \\
\hline Physical exercise & $80 / 15.1$ & $16 / 3.0$ & $1.3(0.7-2.3)$ & \\
\hline
\end{tabular}

${ }^{*}$ Statistically significant at $p$ value 0.05 . 
second year and above. Secondly, the PMDD was assessed based on one cycle of menstrual symptoms experience. This study found a significant association between length of menses and academic performance. Students with short length of menses had low academic performance. This might be due to frequent menstrual pain and mood change that can affect study time and alertness during regular class.

The second objective of this study was to investigate PMS experience and associated factors. In this study, the prevalence of PMDD was $13.8 \%$. This finding was twice the prevalence rate of PMDD in Kuwait students [32], but on the other hand, it was lower than the Pakistani study report [33]. This discrepancy might be due to the difference in sample size, study population, and use of PMDD assessment tool. The Kuwait study [32] included only 110 students from a single department and the data was collected by daily record of severity of symptoms (DRSP) for two menstrual periods. In addition, the Pakistani study [33] has used Moos Menstrual Distress Questionnaire.

In agreement with the previous studies [19, 27, 34], this study revealed that $85.8 \%$ of the students had at least one moderate or severe symptom. However, cross-sectional studies conducted in Thailand [15], Japan [16], and Iran [35] depicted that relatively higher percentage of students had at least one moderate/severe premenstrual symptom. The prevalence rate of moderate/severe PMS in our study was $36.9 \%$. This was higher than some other studies $[10,12,33$, $36,37]$. Furthermore, our study found that $17.0 \%$ of students reported impaired family relationship related to PMS experience.

Similar to earlier studies $[17,38,39]$, this study uncovered that students who had severe pain during menses and heavy menstrual bleeding were more likely to develop PMDD compared to their counterparts. The possible explanation was that the pain and heavy menstrual bleeding increased the sensitivity to rejection by peers, anxiety, tension, and irritability. Students who took nonprescribed drug, particularly pain-killers for self-medication attempt to reduce the physical symptoms of PMS, during menses were more likely to develop PMDD compared to students who have used other options to treat premenstrual symptoms. The possible explanation could be that nonprescribed drugs may cause decreased serotonin, progesterone, and allopregnanolone level, which has been considered as the etiology of PMDD $[40,41]$.

Unlike previous studies [32, 35, 42-44], this study did not show a significant association between PMDD and history of depression, history of any psychiatric morbidity other than depression, history of traumatic event, sleeping hour, history of physical illness, increased educational status, physical exercise, marital status, age at menarche, and maternal history of PMS. This inconsistency may be due to difference in socioeconomic status and health seeking behavior of students.

This study recruited considerably large number of students from all fields of study. In addition, PMDD was ascertaining using a standardized validated scale [45]. Moreover, this study examined the temporal association of PMDD and academic performance. However, this study has certain limitations. First, premenstrual symptoms were not tracked prospectively by daily record of severity of problems (DRSP), which is the gold standard. To differentiate PMDD from other psychiatric morbidities, the American Psychiatric Association recommended PMDD must be confirmed by prospective daily symptom ratings for a minimum of two consecutive symptomatic cycles [4]. Second, due to the crosssectional nature of the study, causal association cannot be assumed between PMDD and identified risk factors, and academic performance and length of menses as well. Third, this study used sensitive questions and self-reported CGPA, and diagnosis of PMDD was made based on self-reported symptoms that possibly added recall and social desirability bias. Lastly, this study was conducted in one institution which might limit external validity of the study results; however, this is possibly compensated by the inclusion of students from different ethnic groups.

\section{Conclusions}

Given premenstrual symptoms are a frequent source of concern to women [11], this study concluded that at least 1 out of 3 students suffered from moderate/severe PMS and 1 out of 10 students fulfilled DSM-5 criteria of PMDD; however, there was no difference in academic performance. Significant association was found between length of menses and academic performance. Severe pain during menses, heavy menstrual bleeding, and taking nonprescribed drug were risk factors of PMDD. To prevent complication such as suicidal ideation [46], student clinic at university should play a leading role to increase awareness and diagnose early and treat PMDD promptly. This study has implication to render further evidence for clinician and researcher. In addition, this study will provide relevant information on PMDD and academic performance at university for stakeholders including government and funding agencies.

\section{Conflicts of Interest}

The authors declare that there are no conflicts of interest regarding the publication of this paper.

\section{Authors' Contributions}

Sisay Mulugeta Alemu and Tesfa Dejenie Habtewold contributed equality to this work and shares first authorship equally. Sisay Mulugeta Alemu conceived and designed the study. Tesfa Dejenie Habtewold organized the data collection, and analyzed and interpreted the data. Tesfa Dejenie Habtewold, Sisay Mulugeta Alemu, and Yohannes Gebreegziabhere Haile wrote the article.

\section{Acknowledgments}

Our in-depth gratitude goes to Debre Berhan University (DBU), Institute of Health Science and Medicine for approval of the study. The authors would like to thank Mr. Seid Beyan, students' academic record center director of DBU, for his collaboration to facilitate data collection. Finally, they 
would like to appreciate supervisors, course coordinators, and female student class representatives.

\section{References}

[1] B. G. Reed and B. R. Carr, "The normal menstrual cycle and the control of ovulation," L. J. De Groot, G. Chrousos, and K. Dungan, Eds., Endotext South Dartmouth (MA): MDText.com, 2000.

[2] A. Walker, "Theory and methodology in premenstrual syndrome research," Social Science and Medicine, vol. 41, no. 6, pp. 793-800, 1995.

[3] World Health Organization. The ICD-10 Classification of Mental and Behavioural Disorders: Diagnostic criteria for research World, 1996.

[4] American Psychiatric Association editor, Diagnostic and Statistical Manual of Mental Disorders, American Psychiatric Publishing, Arlington, Tex, USA, 5th edition, 2013.

[5] de la Gandara Martin J. J. and E. de Diego Herrero, "Premenstrual dysphoric disorder: an epidemiological study," Actas Luso Esp Neurol Psiquiatr Cienc Afines, vol. 24, no. 3, pp. 111-117, 1996.

[6] T. R. Hylan, K. Sundell, and R. Judge, “The impact of premenstrual symptomatology on functioning and treatment-seeking behavior: experience from the United States, United Kingdom, and France," Journal of Women's Health and Gender-Based Medicine, vol. 8, no. 8, pp. 1043-1052, 1999.

[7] S. Ramcharan, E. J. Love, G. H. Fick, and A. Goldfien, “The epidemiology of premenstrual symptoms in A populationbased sample of 2650 urban women: Attributable risk and risk factors," Journal of Clinical Epidemiology, vol. 45, no. 4, pp. 377392, 1992.

[8] H.-U. Wittchen, E. Becker, R. Lieb, and P. Krause, "Prevalence, incidence and stability of premenstrual dysphoric disorder in the community," Psychological Medicine, vol. 32, no. 1, pp. 119$132,2002$.

[9] N. F. Woods, A. Most, and G. K. Dery, "Prevalene of perimenstrual symptoms," American Journal of Public Health, vol. 72, no. 11, pp. 1257-1264, 1982.

[10] I. Lete, J. L. Dueñas, I. Serrano et al., "Attitudes of Spanish women toward premenstrual symptoms, premenstrual syndrome and premenstrual dysphoric disorder: Results of a nationwide survey," European Journal of Obstetrics Gynecology and Reproductive Biology, vol. 159, no. 1, pp. 115-118, 2011.

[11] L. Dennerstein, P. Lehert, and K. Heinemann, "Epidemiology of premenstrual symptoms and disorders," Menopause International, vol. 18, no. 2, pp. 48-51, 2012.

[12] U. Halbreich, J. Borenstein, T. Pearlstein, and L. S. Kahn, "The prevalence, impairment, impact, and burden of premenstrual dysphoric disorder (PMS/PMDD)," Psychoneuroendocrinology, vol. 28, Supplement 3, pp. 1-23, 2003.

[13] L. E. Ross and M. Steiner, "A biopsychosocial approach to premenstrual dysphoric disorder," Psychiatric Clinics of North America, vol. 26, no. 3, pp. 529-546, 2003.

[14] S. Jahanfar, M.-S. Lye, and I. S. Krishnarajah, "The heritability of premenstrual syndrome," Twin Research and Human Genetics, vol. 14, no. 5, pp. 433-436, 2011.

[15] M. Thu and E. O. S. Diaz, "Premenstrual syndrome among female university students in thailand," Assumption University Journal of Technology, vol. 9, no. 3, pp. 158-162, 2006.

[16] T. Takeda, S. Koga, and N. Yaegashi, "Prevalence of premenstrual syndrome and premenstrual dysphoric disorder in
Japanese high school students," Archives of Women's Mental Health, vol. 13, no. 6, pp. 535-537, 2010.

[17] B. A. Issa, A. D. Yussuf, A. W. O. Olatinwo, and M. Ighodalo, "Premenstrual dysphoric disorder among medical students of a Nigerian university," Annals of African Medicine, vol. 9, no. 3, pp. 118-122, 2010.

[18] V. Skrzypulec-Plinta, A. Drosdzol, K. Nowosielski, and R. Plinta, "The complexity of premenstrual dysphoric disorderrisk factors in the population of Polish women," Reproductive Biology and Endocrinology, vol. 8, article 141, 2010.

[19] A. Tenkir, N. Fisseha, and B. Ayele, "Premenstrual syndrom: prevalence and effect on academic and social performances of students in Jimma University," Ethiopian Journal of Health Development, vol. 17, no. 3, pp. 181-188, 2004.

[20] M. H. Balaha, M. A. E. M. Amr, M. S. Al Moghannum, and N. S. Al Muhaidab, "The phenomenology of premenstrual syndrome in female medical students: a cross sectional study," Pan African Medical Journal, vol. 23, no. 5, article 4, 2010.

[21] S.-H. Cheng, C.-C. Shih, Y.-K. Yang, K.-T. Chen, Y.-H. Chang, and Y.-C. Yang, "Factors associated with premenstrual syndrome-A survey of new female university students," Kaohsiung Journal of Medical Sciences, vol. 29, no. 2, pp. 100-105, 2013.

[22] N. K. Chandraratne and N. S. Gunawardena, "Premenstrual syndrome: the experience from a sample of Sri Lankan adolescents," Journal of Pediatric and Adolescent Gynecology, vol. 24, no. 5, pp. 304-310, 2011.

[23] A. C. Eke, J. C. Akabuike, and K. Maduekwe, "Predictors of premenstrual syndrome among Nigerian university students," International Journal of Gynecology and Obstetrics, vol. 112, no. 1, pp. 63-64, 2011.

[24] H. Farrokh-Eslamlou, S. Oshnouei, B. Heshmatian, and E. Akbari, "Premenstrual syndrome and quality of life in Iranian medical students," Sexual \& Reproductive Healthcare, vol. 6, no. 1, pp. 23-27, 2015.

[25] S. H. Hamaideh, S. A. Al-Ashram, and H. Al-Modallal, "Premenstrual syndrome and premenstrual dysphoric disorder among Jordanian women," Journal of Psychiatric and Mental Health Nursing, vol. 21, no. 1, pp. 60-68, 2014.

[26] J. P. Hong, S. Park, H.-R. Wang et al., "Prevalence, correlates, comorbidities, and suicidal tendencies of premenstrual dysphoric disorder in a nationwide sample of Korean women," Social Psychiatry and Psychiatric Epidemiology, vol. 47, no. 12, pp. 19371945, 2012.

[27] F. W. Tolossa and M. L. Bekele, "Prevalence, impacts and medical managements of premenstrual syndrome among female students: cross-sectional study in college of health sciences, Mekelle University, Mekelle, Northern Ethiopia," BMC Women's Health, vol. 14, no. 1, article 52, 2014.

[28] T. B. Pearlstein, U. Halbreich, E. D. Batzar et al., "Psychosocial functioning in women with premenstrual dysphoric disorder before and after treatment with sertraline or placebo," Journal of Clinical Psychiatry, vol. 61, no. 2, pp. 101-109, 2000.

[29] T. Pearlstein and M. Steiner, "Premenstrual dysphoric disorder: Burden of illness and treatment update," Journal of Psychiatry and Neuroscience, vol. 33, no. 4, pp. 291-301, 2008.

[30] R. d. Câmara, C. A. Köhler, B. N. Frey, T. N. Hyphantis, and A. F. Carvalho, "Validation of the Brazilian Portuguese version of the Premenstrual Symptoms Screening Tool (PSST) and association of PSST scores with health-related quality of life," Revista Brasileira de Psiquiatria, 2016.

[31] M. Steiner, M. Peer, E. Palova, E. W. Freeman, M. MacDougall, and C. N. Soares, "The premenstrual symptoms screening tool 
revised for adolescents (PSST-A): prevalence of severe PMS and premenstrual dysphoric disorder in adolescents," Archives of Women's Mental Health, vol. 14, no. 1, pp. 77-81, 2011.

[32] F. E. Omu, R. Al-Marzouk, H. Delles, N. O. Oranye, and A. E. Omu, "Premenstrual dysphoric disorder: prevalence and effects on nursing students' academic performance and clinical training in Kuwait," Journal of Clinical Nursing, vol. 20, no. 1920, pp. 2915-2923, 2011.

[33] S. Tabassum, B. Afridi, Z. Aman, W. Tabassum, and R. Durrani, "Premenstrual syndrome: frequency and severity in young college girls," Journal of the Pakistan Medical Association, vol. 55, no. 12, pp. 546-549, 2005.

[34] M. Delara, F. Ghofranipour, P. Azadfallah, S. S. Tavafian, A. Kazemnejad, and A. Montazeri, "Health related quality of life among adolescents with premenstrual disorders: a cross sectional study," Health and Quality of Life Outcomes, vol. 10, article $1,2012$.

[35] N. M. Bakhshani, M. N. Mousavi, and G. Khodabandeh, "Prevalence and severity of premenstrual symptoms among Iranian female university students," Journal of the Pakistan Medical Association, vol. 59, no. 4, pp. 205-208, 2009.

[36] J. Potter, J. Bouyer, J. Trussell, and C. Moreau, "Premenstrual syndrome prevalence and fluctuation over time: results from a French population-based survey," Journal of Women's Health, vol. 18, no. 1, pp. 31-39, 2009.

[37] N. M. Bakhshani, M. Hosseinbor, Z. Shahraki, and N. Sakhavar, "Premenstrual syndrome symptomatology among married women of fertile age based on methods of contraception (hormonal versus non-hormonal methods of contraception)," Global Journal of Health Science, vol. 6, no. 2, pp. 105-111, 2014.

[38] A. O. Adewuya, O. M. Loto, and T. A. Adewumi, "Premenstrual dysphoric disorder amongst Nigerian university students: prevalence, comorbid conditions, and correlates," Archives of Women's Mental Health, vol. 11, no. 1, pp. 13-18, 2008.

[39] M. Kitamura, T. Takeda, S. Koga, S. Nagase, and N. Yaegashi, "Relationship between premenstrual symptoms and dysmenorrhea in Japanese high school students," Archives of Women's Mental Health, vol. 15, no. 2, pp. 131-133, 2012.

[40] P. Monteleone, S. Luisi, A. Tonetti et al., "Allopregnanolone concentrations and premenstrual syndrome," European Journal of Endocrinology, vol. 142, no. 3, pp. 269-273, 2000.

[41] S. Maharaj and K. Trevino, "A Comprehensive review of treatment options for premenstrual syndrome and premenstrual dysphoric disorder," Journal of Psychiatric Practice, vol. 21, no. 5, pp. 334-350, 2015.

[42] M. Delara and R. L. Woodgate, "Psychological distress and its correlates among university students: a cross-sectional study," Journal of Pediatric and Adolescent Gynecology, vol. 28, no. 4, pp. 240-244, 2015.

[43] C. Sadler, H. Smith, J. Hammond et al., "Lifestyle factors, hormonal contraception, and premenstrual symptoms: The United Kingdom Southampton women's survey," Journal of Women's Health, vol. 19, no. 3, pp. 391-396, 2010.

[44] M. T. E. Shiferaw, M. Wubshet, and D. Tegabu, "Menstrual problems and associated factors among students of Bahir Dar University, Amhara National Regional State, Ethiopia: a crosssectional survey," The Pan African Medical Journal, vol. 17, article 246, 2014.

[45] M. Steiner, M. Macdougall, and E. Brown, "The premenstrual symptoms screening tool (PSST) for clinicians," Archives of Women's Mental Health, vol. 6, no. 3, pp. 203-209, 2003.
[46] D. Ducasse, I. Jaussent, E. Olié, S. Guillaume, J. Lopez-Castroman, and P. Courtet, "Personality traits of suicidality are associated with premenstrual syndrome and premenstrual dysphoric disorder in a suicidal women sample," PLoS ONE, vol. 11, no. 2, Article ID e0148653, 2016. 


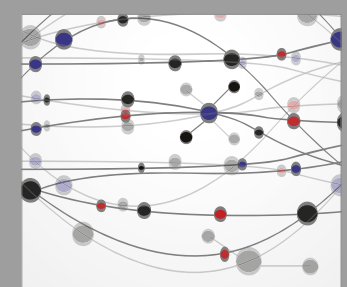

The Scientific World Journal
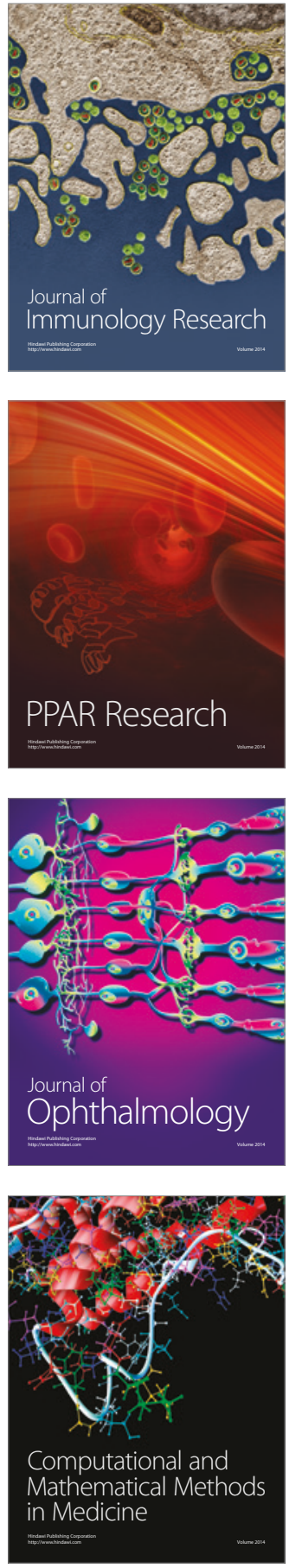

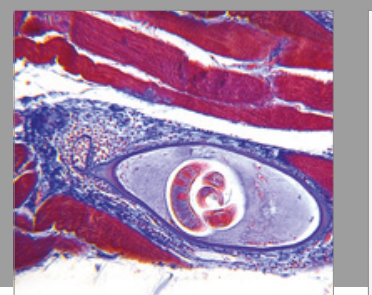

Gastroenterology Research and Practice
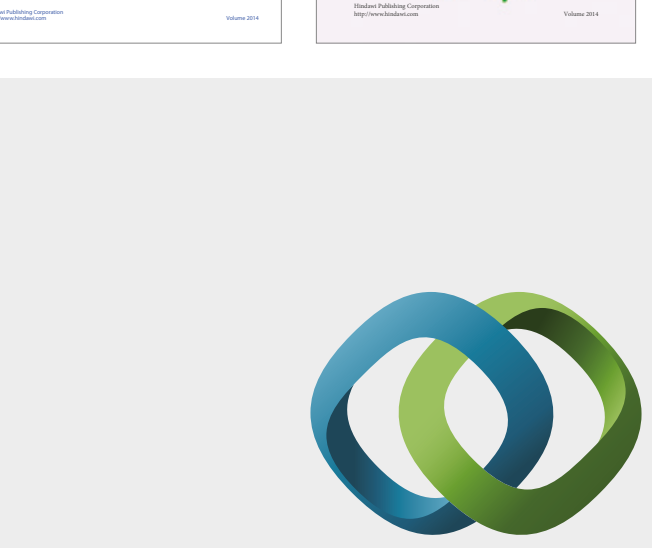

\section{Hindawi}

Submit your manuscripts at

https://www.hindawi.com
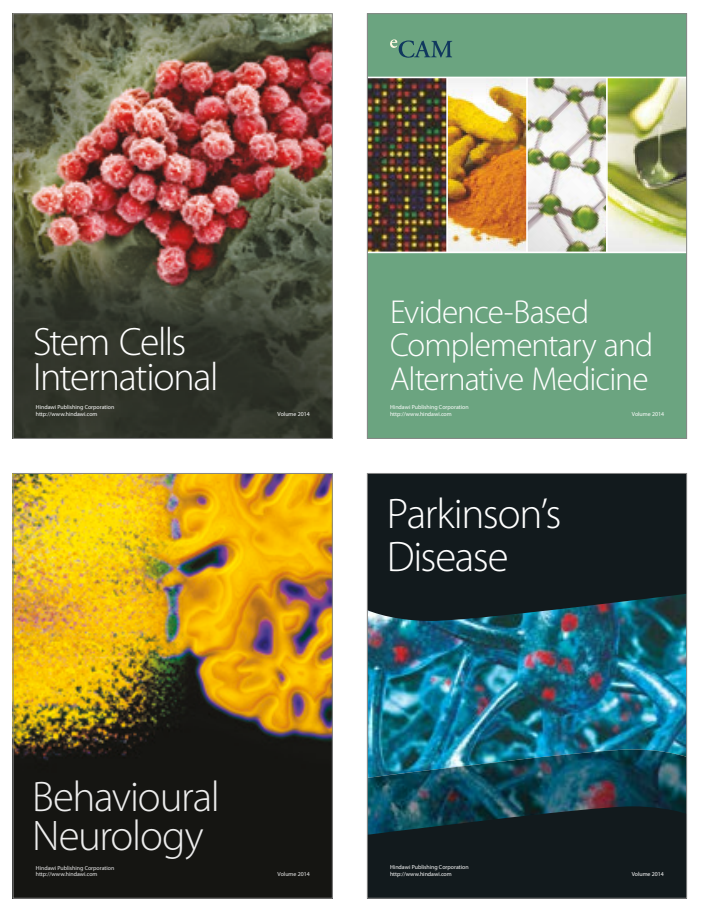
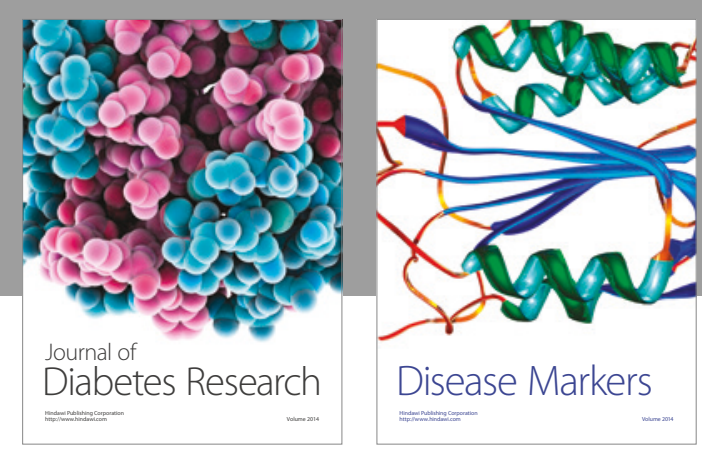

Disease Markers
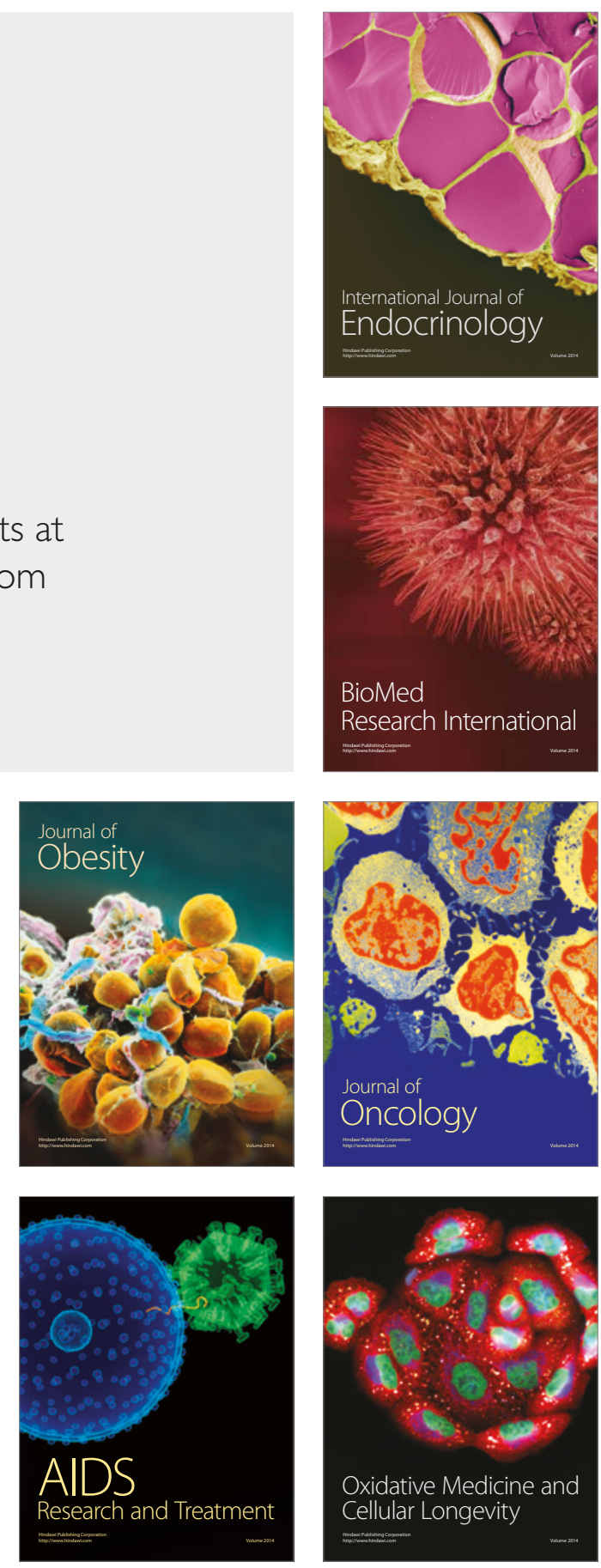